\title{
PREDIKSI KELULUSAN MAHASISWA MENGGUNAKAN K-NEAREST NEIGHBOR BERBASIS PARTICLE SWARM OPTIMIZATION
}

\author{
Nursetia wati, Abdul Syukur, A. Zainul Fanani \\ Pascasarjana Teknik Informatika Universitas Dian Nuswantoro Semarang \\ E-mail: nursetiawati.imran@gmail.com
}

\begin{abstract}
Completion of studies of students in a timely manner is one measure of the quality of higher education, as well as in finding a job. Anticipation that can be done is by predicting graduation, with these predictions do evaluation efforts in organizing lectures at the faculty or study program. The data in this study is the student data Gorontalo State University Faculty of Education and Faculty of Engineering from 2008 until 2012. From 5104 the total number of records is done with attribute data sorting empty, so the existing data into 2312 record. The algorithm used in this study is a K-Nearest Neighbor which will then be optimized using Particle Swarm Optimization. By using the technique Fold Cross Validation on K-Nearest Neighbor algorithm produces the highest accuracy 88.58 on the value of $k=14$. The next test using particle swarm optimization algorithm to get the highest accuracy on the population size $=10$ with accuracy of $89.14 \%$.
\end{abstract}

1. Pendahuluan

1.1 Latar Belakang

Berdasarkan data pada Fakultas Ilmu Pendidikan Univeristas Negeri Gorontalo strata D2 lulusan tahun 2006 sampai dengan tahun 2012 menunjukan rata-rata presentasi kelulusan tepat waktu atau menempuh studi dalam kurun waktu dua tahun yaitu sebesar $89 \%$ dan untuk presentasi mahasiswa yang melebihi waktu studi atau lulus tidak tepat waktu sebesar $10 \%$, sedangkan untuk S1 yang ditempuh dalam kurun waktu 4 tahun dengan lulusan sejak tahun 2005 sampai tahun 2009 sebesar $77 \%$ dan untuk mahasiswa yang melebihi jangka waktu studi atau lulus tidak tepat waktu sebesar $28 \%$. Untuk data mahasiswa pada Fakultas Teknik strata D3 lulusan tahun 2006 sampai tahun 2012 yang ditempuh dalam kurun waktu 3 tahun rata-rata presentasi yaitu sebesar $20 \%$ dan mahasiswa lulus tidak tepat waktu atau melebihi jangka waktu studi yang telah ditetapkan sebesar 71\%, sedangkan pada strata S1 lulusan pada tahun 2007 sampai dengan tahun 2012 menunjukan presentasi mahasiswa yang lulus tepat waktu yaitu sebesar 73\% dan presentasi kelulusan untuk mahasiswa tidak tepat waktu yaitu sebesar 18\% [1].

Dengan data yang ada terlihat presentasi kelulusan tidak tepat waktu terutama pada Fakultas Teknik sangatlah tinggi, kondisi tersebut mendorong setiap program studi terus meningkatkan kelulusan agar saran mutu bias tercapai.

Pada penelitian Banjarsari [2] yang menerapkan K-Optimal pada algortima $K$ Nearest Neighbor untuk memprediksi kelulusan tepat waktu mahasiswa, dalam penelitiannya Metode $k$-Fold Cross Validation dan Uji Akurasi menjadi salah satu metode yang digunakan untuk mengetahui nilai $\mathrm{K}$. selain itu juga ada penelitian mengenai klasifikasi untuk memprediksi kelulusan Mahasiswa menggunakan algortima C5.0 dengan kategori IPK dan lama studi sebelumnya telah dilakukan oleh Irene [3] dalam penerapan algoritma $C 5.0$ menghasilkan akurasi data untuk IPK sebesar 79,3\% dan lama studi sebesar $86,7 \%$.

Sesuai dengan data dan penelitian yang telah dilakukan dengan akurasi data berdasarkan hasil penelitian tersebut, Dengan menggunakan Algortima K-Nearest Neighbor berbasis Particle Swarm Optimization diharapkan dapat mengetahui nilai 
akurasi untuk prediksi kelulusan mahasiswa Fakultas Teknik dan Fakultas Ilmu Pendidikan Universitas Negeri Gorontalo lebih meningkat.

\subsection{Rumusan Masalah}

Dalam memprediksi kelulusan mahasiswa sangatlah penting untuk menjadi bahan pertimbangan bagi fakultas agar dapat melakukan tindak lanjut dalam menghadapi mahasiswa yang nantinya berpotensi lulus tidak tepat waktu. Dan berdasarkan latar belakang permasalahan yang ada, terlihat dalam penelitian sebelumnya yang menggunakan algoritma K-Nearest Neighbor hasil akurasi yang didapatkan masih terbilang kurang. Untuk itu diperlu ditambahkan algoritma Particle Swarm Optimization untuk lebih meningkatkan akurasi dalam memprediksi kelulusan mahasiswa yang nantinya dengan nilai yang didapatkan dapat menjadi parameter tersendiri untuk fakultas agar bisa mengatasi mahasiswa yang berpotensi lulus tidak tepat waktu.

\subsection{Tujuan Penelitian}

Sesuai rumusan masalah diatas maka tujuan penelitian yaitu mendapatkan hasil akurasi yang lebih baik dalam kelulusan mahasiswa mengunakan algoritma $K$-Nearest Neighbor berbasis Particle Swarm Optimization.

\subsection{Manfaat Penelitian}

Manfaat yang didapatkan pada penelitian ini adalah Dapat melihat keakurasian data yang lebih baik dari algoritma yang telah diterapkan sebelumnya untuk lama studi mahasiswa.

\section{Tinjauan Pustaka}

\subsection{Penelitian Terkait}

Pada penelitian yang dilakukan oleh Mutiara Ayu Banjarsari, dkk [2] yang berjudul "Penerapan K-Optimal Pada Algoritma K-Nearest Neighbor untuk Prediksi Kelulusan Tepat Waktu Mahasiswa Program Studi Ilmu Komputer Fmipa Unlam Berdasarkan IP Sampai Dengan Semester 4". Pada penelitiannya menjelaskan Metode $k$ Fold Cross Validation dan Uji Akurasi digunakan untuk mengetahui nilai k-Optimal. Dalam pengujian untuk mendapatkan k-Optimal peneliti menggunakan metode Metode $k$ Fold Cross Validation dengan pengulangan sebanyak lima kali percobaan. Langkah metode $k$-Fold Cross Validation ini adalah dengan membagi data training yang berjumlah 110 menjadi 5 bagian yang sama yaitu 22 buah data tiap bagian data testing. Data training ini sebelumnya telah dilakukan pengacakan data.

\subsection{Landasan Teori}

\subsubsection{Data Mining}

Alasan utama mengapa data mining diperlukan adalah karena adanya sejumlah besar data yang dapat digunakan untuk menghasilkan informasi dan knowledge yang berguna. Informasi dan knowledge yang didapat tersebut dapat digunakan pada banyak bidang, mulai manajemen bisnis, control produksi, kesehatan, dan lain-lain.

\subsubsection{K-Nearest Neighbor (KNN)}

Dalam K-Nearest Neighbor, kita mengelompokkan suatu data baru bedasarkan jarak data baru ke beberapa data/tetangga (Neighbor) terdekat. Dalam hal ini jumlah data/tetangga terdekat di tentukan oleh user yang diyatakan dengan k [4] . K-Nearest Neighbor merupakan salah satu model yang digunakan dalam algoritma supervised yang hasil instance diklasifikasikan berdasarkan mayoritas dari kategori pada $K$-Nearest Neighbor. K-Nearest Neighbor bekerja bersadarkan jarak minimum dari data baru ke tetangga terdekat yang sudah ditetapkan. Tujuan dari algoritma ini adalah mengklasifikasikan obyek baru berdasarkan atribut dan training sample. Jauh dekatnya tetangga biasanya dihitung berdasarkan Euclidean Distance yang direpresentasikan sebagai berikut : 


$$
\mathrm{E}(x, y)=\sqrt{\sum_{i=0}^{n}(x i-y i)^{2}}
$$

Keterangan:

$$
\begin{aligned}
& x i=\text { Sample Data } \\
& y i=\text { Data uji atau Testing } \\
& n=\text { Deimensi Data } \\
& i=\text { Variable Data }
\end{aligned}
$$

Algoritma K-Nearest Neighbor (KNN) yaitu:

1. Mentukan parameter K, K merupakan Tetangga terdekat

2. Setelah mendapatkan $\mathrm{K}$, kemudian hitung jarak antara data baru dengan semua data training

3. Urutkan jarak tersebut dan tetapkan tetangga terdekat berdasarkan jarak minimum ke-K

4. Periksa kelas dari tetangga terdekat

5. Gunakan mayoritas sederhana dari kelas tetangga terdekat sebagai nilai prediksi data baru. NN [5]

Berikut merupakan penjelasan dari parameter yang digunakan dalam persamaan K-

\section{Tabel 2.8 Parameter- Parameter K-NN}

\begin{tabular}{|c|l|}
\hline Parameter & \multicolumn{1}{|c|}{ Keterangan } \\
\hline Sample & $\begin{array}{l}\text { Matriks dimana baris merupakan data, kolom merupakan fiture. } \\
\text { Sample merupakan data uji yang akan diklasifikasikan ke dalam } \\
\text { kelas. Matriks Sample harus mempunya jumlah kolom (fitur) yang } \\
\text { sama dengan matriks traning }\end{array}$ \\
\hline Traning & $\begin{array}{l}\text { Matriks yang digunakan untuk mengelompokan baris di dalam } \\
\text { matriks sample. Matriks traning harus mempunya jumlah kolom } \\
\text { yang sama dengan matriks sample. Setiap baris dalam matriks } \\
\text { traning mempunyai relasi kelas pada baris yang sama di matriks } \\
\text { group. }\end{array}$ \\
\hline Group & $\begin{array}{l}\text { Vector (matriks 1 kolom) yang setiap barisnya menyatakan kelas } \\
\text { dari baris yang sama matriks traning }\end{array}$ \\
\hline K & $\begin{array}{l}\text { Jumlah tetangga terdekat yang digunakan untuk klasifikasi. Nilai } \\
\text { defaulnya dalah 1 }\end{array}$ \\
\hline Distance & $\begin{array}{l}\text { String yang menyatakan matriks jarak yang digunakan untuk } \\
\text { mencari tetangga terdekat. Pilihannya 'euclidean', jarak Euclidean } \\
\text { (default)'cityblok' jarak Manhattan atau jumlah absolute } \\
\text { perbedaan nilai antar fitur 'cosine' jarak 1 - cos (sudut antara dua } \\
\text { titik) 'correlation', jarak 1 - korelasi di antara titik (nilai sekuen) } \\
\text { 'hamming', jarak presentase bit yang berbeda (cocok untuk data } \\
\text { biner). }\end{array}$ \\
\hline
\end{tabular}

\subsubsection{Particle Swarm Optimization (PSO)}

Algoritma Particle Swarm Optimization. (PSO) telah terinspirasi dari tingkah laku hewan koloni seperti, lebah, burung dan rayap. Ada beberapa parameter pada PSO yaitu berupa kecepatan maksimum, posisi, berat inersia kecepatan dan konstanta percepatan. Khoirul Mu'arif [3] mengatakan PSO adalah model optimasi heuristic global yang diperkenalkan oleh Kennedy Eberthart pada tahun 1995. Perilaku terhadap kawasan burung dan ikan. Partikel pada PSO juga sering dikaitkan dengan kecepatan partikel terbang melalui ruang pencarian dengan kecepatan dinamis yang disesuaikan untuk perilaku histori mereka.

Setiap partikel dalam PSO Juga dikaitkan dengan kecepatan partikel terbang melalui ruang pencarian dengan kecepatan yang dinamis disesuaikan untuk perilaku 
histori mereka. Oleh karena itu, partikel memiliki kecendurungan untuk terbang menuju daerah pencarian yang lebih baik dan lebih baik selama proses pencarian.

Secara singkat PSO dimulai dari inisialisasi populasi hingga penghentian komputasi, seperti algoritma berikut [5].

a. Inisialisai populasi (populasi dan kecepatan acak) dalam hyperspace

b. Evaluasi fitness partikel individu

c. Memodifikasi kecepatan berdasarkan terbaik sebelumnya (previous best: pbest) dan terbaik global atau local (global or neighborhood best: gbest or lbest)

d. Hentikan berdasarkan beberapa kondisi

e. Kembali ke langkah (b)

Pencarian solusi optimal dalm PSO akan dilakukan sampai semua memiliki skema solusi yang sama atau ketika iterasi tertinggi telah tercapai.

Velocity pada metode PSO dituliskan sebagai berikut:

$v i, d=w * v i, d+c 1 * R *($ pbesti, $d-x i, d)+c 2 * R *($ gbestd $-x i, d)$

Dan perhitungan posisinya :

$x i d=x i, d+v i, d$

Dimana :

$$
\begin{array}{ll}
V_{i}, \mathrm{~d} & =\text { Kecepatan Partikel } i \text { saat iterasi } i \\
w & =\text { Bobot inersia } \\
c_{1} \text { dan } c_{2} & =\text { konstanta ekeselerasi (Learning rate) } \\
\mathrm{R} & =\text { Bilangan random }(0-1) \\
x i, d & =\text { Posisi saat ini dari partikel } i \text { pada iterasi } i \\
\text { pbesti } & =\text { Posisi terbaik sebelumnya dari partikel } i \\
\text { gbestd } & =\text { Partikel terbaik diantara semua partikel dalm satu koloni } \\
n & =\text { Jumlah Partikel dalam koloni } \\
d & =\text { Demensi }
\end{array}
$$

\subsubsection{Confusion Matrix}

Dalam melakukan evaluasi terhadap suatu model klasifikasi berdasarkan perhitungan objek testing mana yang diprediksi benar dan mana yang diprediksi tidak benar. Perhitungan tersebut digambarkan dalam tabel yang disebut confusion matrix. Confusion matrix merupakan data set yang hanya memiliki dua kelas, kelas yang satu sebagai positif dan kelas yang lain sebagai negative. Terlihat pada gambar di bawah tabel confusion matrix [4]:

Tabel 2.9 Confusion Matrix untuk dua kelas

\begin{tabular}{|c|c|c|c|}
\hline \multirow{2}{*}{ CLASSIFICATION } & \multicolumn{3}{|c|}{ PREDICTED CLASS } \\
\cline { 2 - 4 } & Class = Yes & $\begin{array}{c}\text { Class = Yes } \\
\text { (true positive }-\mathrm{TP})\end{array}$ & $\begin{array}{c}\mathrm{b} \\
\text { (false negative }-\mathrm{FN})\end{array}$ \\
\hline \multirow{2}{*}{ OBSERVED CLASS } & Class = No & $\begin{array}{c}\mathrm{c} \\
\text { (false positive }-\mathrm{FP})\end{array}$ & $\begin{array}{c}\mathrm{d} \\
(\text { true negatife }-\mathrm{TP})\end{array}$ \\
\cline { 2 - 4 } &
\end{tabular}

Berdasarkan tabel di atas true positive adalah jumlah record positive yang diklasifikasikan sebagai positive, false positive adalah jumlah record negative yang diklasifikasikan sebagai positive, false negatives adalah jumlah record positive yang diklasifikasikan sebagai negative, true negatives adalah jumlah record negatif yang diklasifikasikan sebagai negative, setelah itu masukkan dataset. Setelah dataset dimasukkan ke dalam confusion matrix, akan menghasilkan nilai seperti jumlah sensitivity (recall), specificity, precision dan accuracy. Sensitivity digunakan untuk 
membandingkan jumlah TP terhadap jumlah record yang positif sedangkan specificity adalah perbandingan jumlah $\mathrm{TN}$ terhadap jumlah record yang negatif. Untuk menghitung digunakan persamaan di bawah ini [4]:

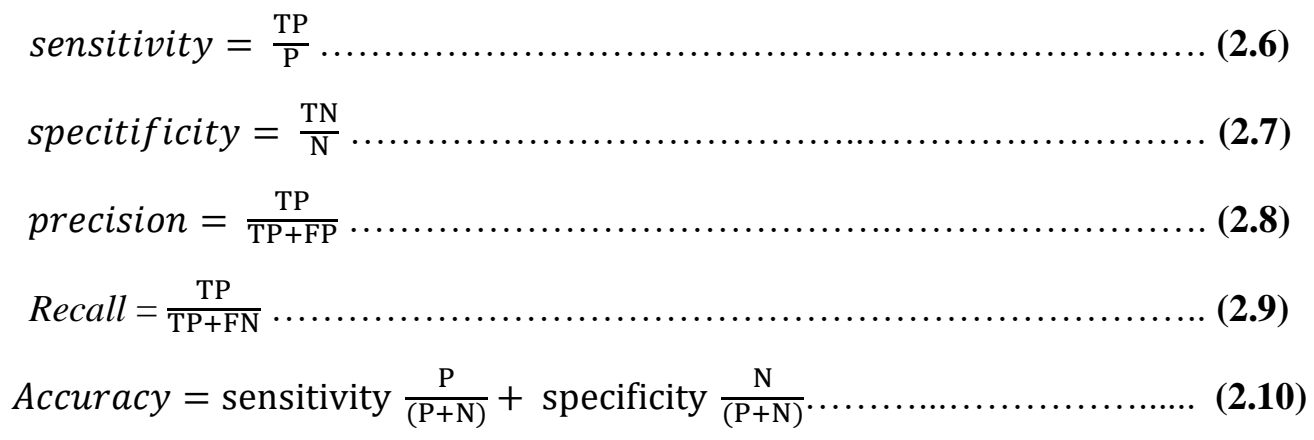

Accuracy $=$ sensitivity $\frac{\mathrm{P}}{(\mathrm{P}+\mathrm{N})}+$ specificity $\frac{\mathrm{N}}{(\mathrm{P}+\mathrm{N})}$.

Keterangan:

$$
\begin{array}{ll}
\mathrm{TP} & =\text { jumlah } \text { true positives } \\
\mathrm{TN} & =\text { jumlah } \text { true } \text { negatives } \\
\mathrm{P} & =\text { jumlah } \text { record } \text { positif } \\
\mathrm{N} & =\text { jumlah } \text { tupel } \text { negatif } \\
\mathrm{FP} & =\text { jumlah false positives } \\
\mathrm{FN} & =\text { jumlah false negative }
\end{array}
$$




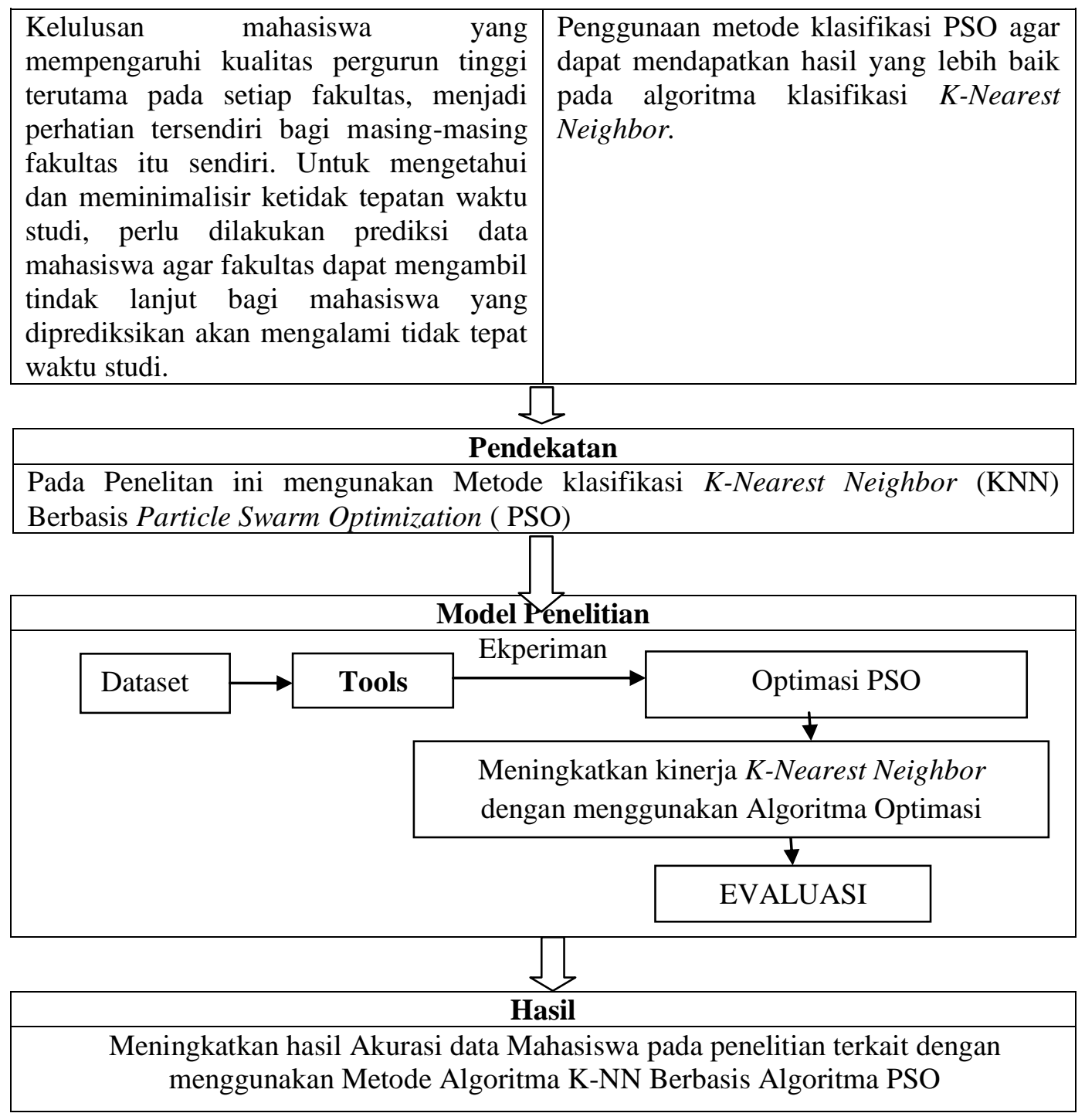

3. Metode Penelitian

3.1 Model Penelitian

Pada penelitian ini digunakan metode ekperimen, dimana dapat dilihat pada gambar di bawah ini: 


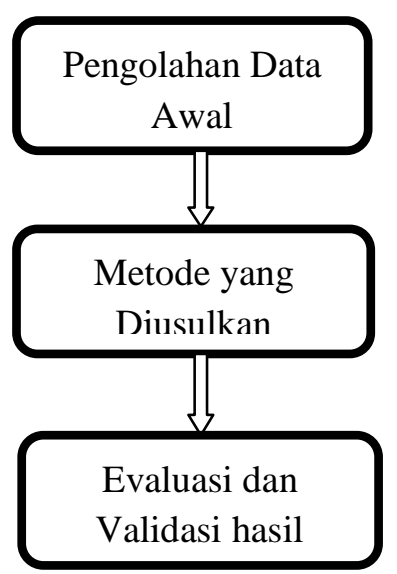

Gambar 3.1 Langkah Metode Penelitian

\subsubsection{Pengumpulan data}

Data yang digunakan pada penelitian ini berasal dari penelitian Wandira Irene [3] untuk mendapatkan data mahasiswa. Dari data yang telah dikumpulkan terdapat jumlah variable data, untuk Fakultas Ilmu Pendidikan 4242 record dan Fakultas Teknik 862 record yang masing-masing fakultas memiliki atribut bernilai nominal dan pastinya setiap tahun mengalami perubahan pada jumlah record. Dan dataset dari kedua fakultas ini telah digabungkan menjadi satu yang memiliki jumlah 5.104 record.

3.1.2 Pengolahan data Awal

Setelah melakukan pengumpulan data yang menghasilkan 4242 record untuk Fakultas Ilmu Pendidikan dan 862 record untuk Fakultas Teknik yang seluruhannya berjumlah 5.104 record. Dalam pengolahan data (Preparation Data) awal ada beberapa proses yang harus di lakukan yaitu:

\subsubsection{Pembersihan Data Pembersihan Data}

Dalam proses ini dilakukan pembersian data dengan cara menghapus data yang kosong atau tidak terisi pada beberapa atribut, dan data yang sulit diolah saat melakukan pengujian, pembersian data ini dilakukan untuk mendapatkan dataset yang berkualitas.

\subsubsection{Menentukan Atribut}

Setelah melakukan penghapusan data, langkah selanjutnya yaitu menentukan atribut yang digunakan saat pengujian nanti. Sebelumnya pada dataset mahasiswa ini terdapat 16 atribut yang diantranya Nama, Nim, Alamat, dan seterusnya. 16 atribut tersebut tidak semuanya digunakan karena dalam memprediksi nanti atribut seperti Nama, Nim dan Alamat tidak mempengaruhi hasil prediksi. Atribut- atribut yang digunakan terlihat pada tabel di bawah ini:

Tabel 3.4 Kedudukan Atribut yang akan digunakan

\begin{tabular}{|l|c|c|}
\hline \multicolumn{1}{|c|}{ Atribut } & \multicolumn{2}{c|}{ Type } \\
\hline Nama Mhs & $\times$ & Nominal \\
\hline Strata & $\sqrt{ }$ & Nominal \\
\hline
\end{tabular}




\begin{tabular}{|l|c|c|}
\hline Sex & $\sqrt{ }$ & Nominal \\
\hline Jurusan & $\sqrt{ }$ & Nominal \\
\hline Kelas & $\sqrt{ }$ & Nominal \\
\hline Seleksi & $\sqrt{ }$ & Nominal \\
\hline Pekerjaan Ayah & $\times$ & Nominal \\
\hline Pekerjaan Ibu & $\times$ & Nominal \\
\hline Pendidikan Ayah & $\times$ & Nominal \\
\hline Pendidikan Ibu & $\times$ & Nominal \\
\hline Penghasilan Ayah & $\sqrt{ }$ & Nominal \\
\hline Penghasilan Ibu & $\sqrt{ }$ & Nominal \\
\hline Asal Sekolah & $\times$ & Nominal \\
\hline Asal Daerah & $\times$ & Nominal \\
\hline IPK & $\sqrt{ }$ & Nominal \\
\hline Lama Studi & $\sqrt{ }$ & Nominal \\
\hline
\end{tabular}

Proses pengolahan data awal dapat dilihat pada gambar di bawah ini:

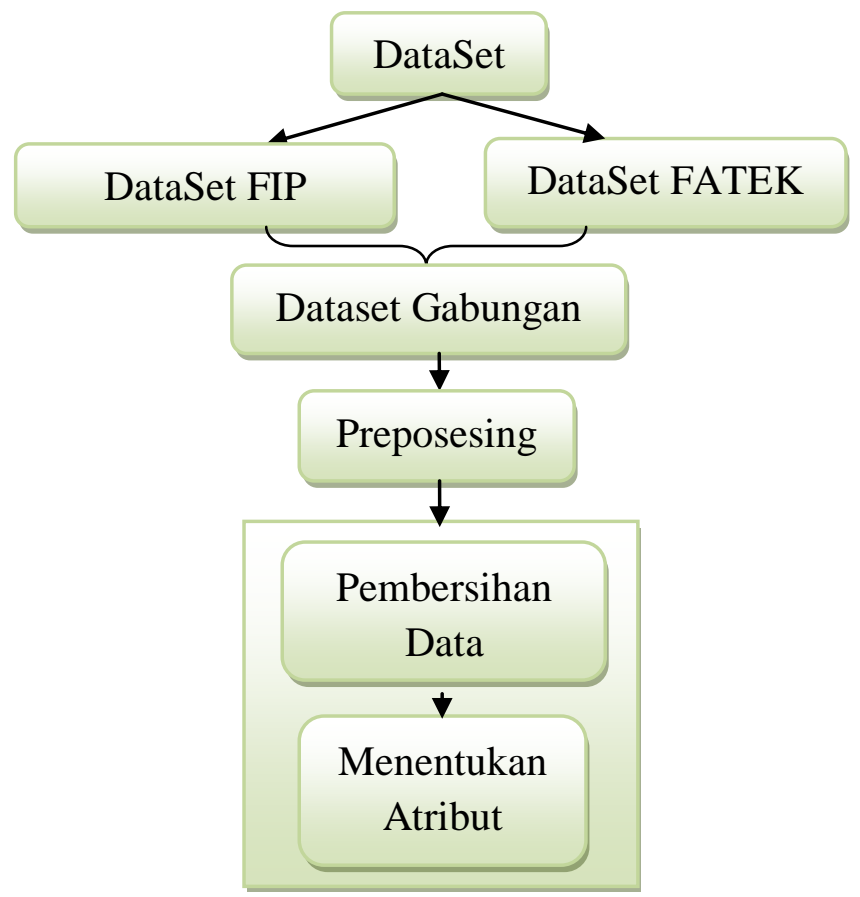

Gambar 3.4 Proses Pengolahan Dataset Mahasiswa

Berdasarkan gambar di atas, dapat terlihat proses pengolahan data yang diawali dengan menggabungkan dataset FIP dan FATEK dalam dataset gabungan, setelah dataset tergabung selanjutnya melakukan preposesing yang bertujuan untuk mendapatkan dataset yang berkualitas, setelah itu melakukan pengujian dengan metode.

3.1.2.3 Metode yang diusulkan

Pada penelitian ini dilakukan ekperimen dengan metode yang diusulkan yaitu penggunaan metode K-Nearest Neighbor berbasis Particle Swarm Optimization yang nantinya akan digunakan pada proses perhitungan untuk mendapatkan hasil akurasi dengan melakukan pengujian menggunakan $k$-fold cross validation, kemudian melakukan evaluasi dan validasi hasil dengan confution matrix agar dapat melihat hasil accuracy yang mungkin lebih meningkat. Motode proses yang diusulkan dapat dilihat di bawah ini: 


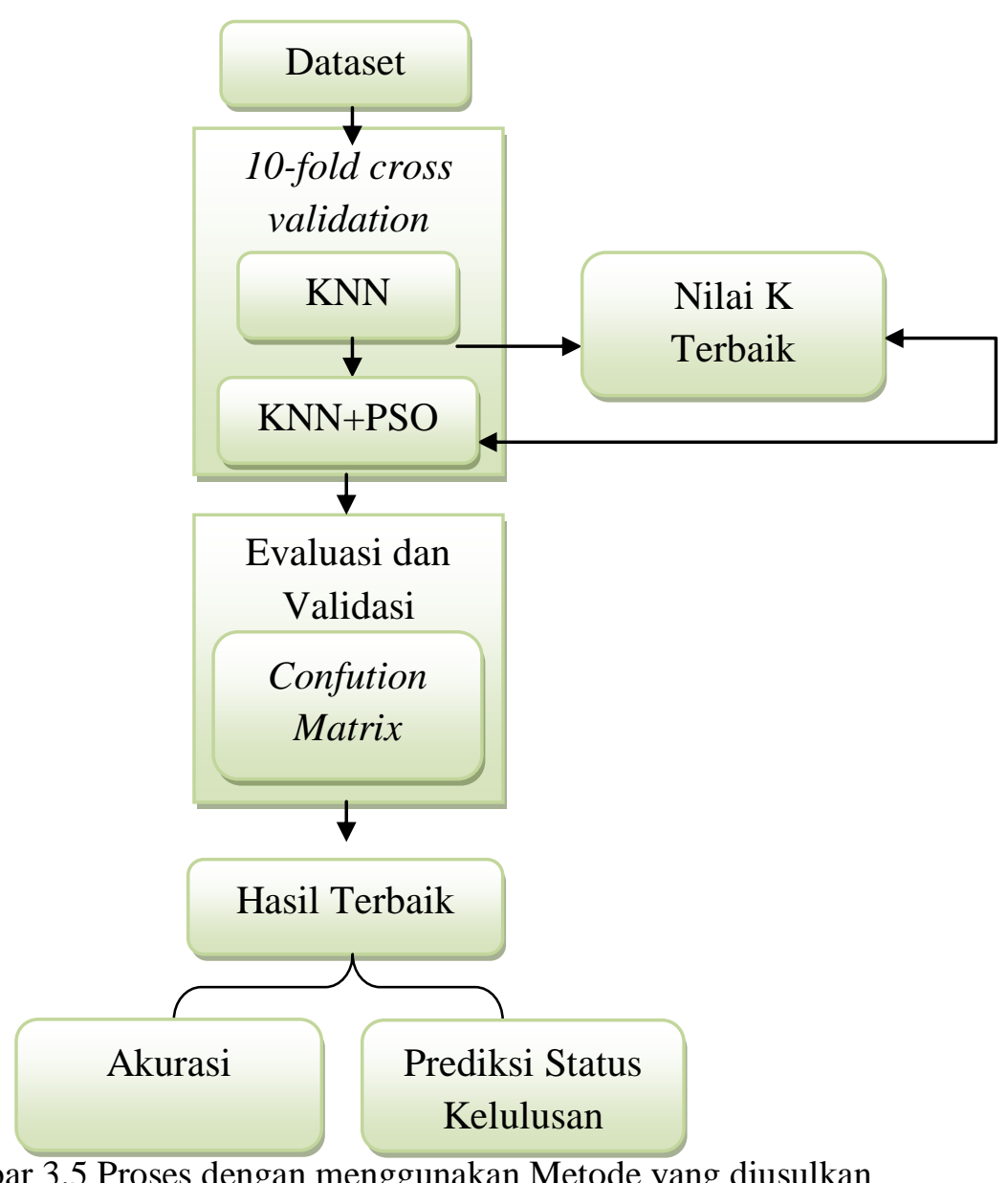

Gambar 3.5 Proses dengan menggunakan Metode yang diusulkan

Setelah menggambarkan proses dengan menggunakan Metode yang diusulkan seperti di atas, maka selanjutnya melakukan perhitungan untuk mendapatkan nilai terbaik dengan mengunakan K-Nearest Neighbor berbasis Particle Swarm Optimization yang dalam perhitungan manualnya berdasarkan tahapan-tahapan.

3.2 Evaluasi dan Validasi Hasil

Pada tahap evaluasi akurasi diukur dengan confusion matrix untuk pengukuran model, Hasil dari confusion matrix dapat menggambarkan berupa hasil akurasi yaitu, tepat waktu dan tidak tepat waktu. Analisis terhadap hasil dari hasil evaluasi confusion matrix berupa nilai Accuracy yang dapat dihitung dengan persamaan (2.10), dan tabel Confusion Matrix terlihat pada gambar di bawah ini:

Tabel 3.18 Contoh confusion matrix K-NN

\begin{tabular}{|l|c|cc|}
\hline Confusion Matrix & True TEPAT & True TIDAK & TEPAT \\
& WAKTU & WAKTU & \\
\hline Pred. TEPAT WAKTU & TP & FN & \\
\hline Pred. TIDAK TEPAT WAKTU & FP & TP \\
\hline
\end{tabular}

\section{Hasil Penelitian}

Terlihat dari tujuan penulisan ini yaitu mendapatkan hasil akurasi dengan menggunakan data kelulusan mahasiswa berdasarkan penelitian terkait mengunakan algoritma K-Nearest Neighbor berbasis Particle Swarm Optimization. Tujuan dari 
menggunakan algoritma Particle Swarm Optimization ini untuk melakukan penyesuaian bobot atribut yang saat proses traning dan testing mengunakan algoritma K-Nearest Neighbor. Namun, sebelum melakukan pembobotan penulis terlebih dahulu melakukan proses pengumpulan data yang menghasilkan jumlah 5.104 record kemudian melakukan pengolahan data awal dengan hasil jumlah dataset yang berjumlah 2312 record, jumlah tersebut didapatkan dari hasil melakukan pembersih data kosong pada setiap atribut yang terdapat pada data tersebut. Setelah melakukan pembersihan langkah selanjutnya yaitu penentuan atribut yang menghasilkan 9 atribut yang digunakan pada penelitian ini. Setelah menentukan atribut-atribut yang berpengaruh pada lama studi mahasiswa selanjutnya membagi dua dataset untuk melakukan proses pengujian berikutnya, yaitu melakukan pembobotan atribut menggunakan Particle Swarm Optimization. Namun sebelum melakukan pembobotan atribut, terlebih dahulu mencari nilai $\mathrm{K}$ terbaik menggunakan Algoritma K-Nearest Neighbor, dan hasil yang didapatkan digunakan dalam pengukuran hasil accuracy algoritma K-Nearest Neighbor berbasis Particle Swarm Optimization.

4.1 Hasil Pengujian Menggunakan Algoritma K-Nearest Neighbor

Dalam tahap pengujian model penelitian ini menggunakan Cross Validation yang merupakan teknik pengujian dengan cara membagi dua data secara acak. Dalam pencariannya menghasilkan nilai accuracy pada algoritma K-Nearest Neighbor dengan menggunakan number of validation

Di bawah ini terlihat tabel hasil pengujian nilai $\mathrm{K}$ terbaik seperti:

Tabel 4.1 Hasil Pengujian Nilai K

\begin{tabular}{|c|c|}
\hline Nilai K & Accuracy \\
\hline $\mathrm{K}=1$ & $82.28 \%$ \\
\hline $\mathrm{K}=2$ & $82.28 \%$ \\
\hline $\mathrm{K}=3$ & $87.37 \%$ \\
\hline $\mathrm{K}=4$ & $87.54 \%$ \\
\hline $\mathrm{K}=5$ & $87.97 \%$ \\
\hline $\mathrm{K}=6$ & $87.41 \%$ \\
\hline $\mathrm{K}=7$ & $88.28 \%$ \\
\hline $\mathrm{K}=8$ & $87.89 \%$ \\
\hline $\mathrm{K}=9$ & $88.41 \%$ \\
\hline $\mathrm{K}=10$ & $88.32 \%$ \\
\hline $\mathrm{K}=11$ & $88.45 \%$ \\
\hline $\mathrm{K}=12$ & $88.45 \%$ \\
\hline $\mathrm{K}=13$ & $88.45 \%$ \\
\hline $\mathrm{K}=14$ & $88.58 \%$ \\
\hline $\mathrm{K}=15$ & $88.58 \%$ \\
\hline $\mathrm{K}=\mathrm{n}$ & $\ldots$. \\
\hline
\end{tabular}

Berdasarkan perolehan nilai accuracy di atas terlihat, nilai accuracy $\mathrm{K}$ tertinggi terdapat pada nilai $\mathrm{K}=14$ yaitu berjumlah $88.58 \%$ hasil ini diperoleh dalam pengujian dataset yang secara otomatis terbagi menjadi traning dan testing saat menggunakan Fold Cross Validation yang tingkat akurasinya dipengaruhi oleh dataset yang digunakan, dan hasil accuracy tertinggi dapat digambarkan dalam tabel confusion matrix, seperti di bawah ini:

Tabel 4.2 Tingkat accuracy Algoritma K-Nearest Neighbor dengan Nilai K = 14 accuracy: $88.58 \%+/-$ $1.97 \%$ (mikro: $88.58 \%$ ) 


\begin{tabular}{|l||l||l|l|}
\hline Klasifikasi Nilai K=14 & $\begin{array}{l}\text { rue TIDAK TEPAT } \\
\text { WAKTU }\end{array}$ & true TEPAT WAKTU & $\begin{array}{l}\text { lass } \\
\text { precision }\end{array}$ \\
\hline \hline $\begin{array}{l}\text { pred. TIDAK TEPAT } \\
\text { WAKTU }\end{array}$ & 272 & 70 & $79.53 \%$ \\
\hline \hline pred. TEPAT WAKTU & 193 & 1768 & $90.16 \%$ \\
\hline \hline class recall & $58.49 \%$ & $96.19 \%$ & \\
\hline
\end{tabular}

Untuk memperoleh persentase hasil akurasi Algoritma K-Nearest Neighbor dengan Nilai $\mathrm{K}=14$ dapat dicari dengan rumus:

- Sensitivity untuk nilai positif

$$
\begin{aligned}
\text { Sensitivity } & =\frac{T P}{P} \\
& =\frac{272}{465} * 100 \\
& =58.49 \%
\end{aligned}
$$

- Specificity untuk nilai Negatif

$$
\begin{aligned}
\text { Specificity }= & \frac{\mathrm{TN}}{\mathrm{N}} \\
& =\frac{1769}{1838} * 100 \\
& =96.19 \%
\end{aligned}
$$

- Accuracy $=$ Sensitivity $\frac{P}{(P+N)}+$ Specificity $\frac{N}{(P+N)}$

$$
\begin{aligned}
& =58.49 * \frac{465}{(465+1838)}+96.19 * \frac{1838}{(465+1838)} * 100 \\
& =58.49 * 0.201911+96.19 * 0.798089 * 100 \\
& =88.58 \%
\end{aligned}
$$

4.2 Hasil Pembobotan dan Pengujian menggunakan Algoritma K-Nearest Neighbor berbasis Particle Swarm Optimization.

Pada algoritma Particle Swarm Optimization digunakan untuk pembobotan atribut dengan melakukan proses pencarian nilai $\mathrm{K}$ terbaik berdasarkan algoritma $K$-Nearest Neighbor terlebih dahulu, setelah mendapatkan nilai accuracy terbaik dengan mengubah parameter pada K-Nearest Neighbor kemudian tentukan inisialisasi partikel pada data (x), inisialisasi kecepatan partikel (v) secara random, untuk mendapatkan parameter terbaik yang terbentuk perlu di lakukan Evaluasi fitness dari masing-masing partikel berdasarkan posisinya, kemudian Tentukan partikel dengan fitness terbaik, dan tetapkan sebagai Gbest. Untuk setiap partikel, Pbest awal akan sama dengan posisi awal. Hasil ekperimen mengunakan RapidMiner dalam Proses pembobotan atribut yang berjumlah 2312 record, menggunakan 9 atribut yang mempengaruhi hasil klasifikasi dalam memprediksi kelulusan mahasiswa yang atribut status kelulusan menjadi labelnya. Atribut-atribut tersebut memiliki bobot disetiap atribut yaitu seperti di bawah ini: 
Tabel 4.3 Hasil pembobotan atribut mengunakan K terbaik pada Algoritma Particle Swarm Optimization

\begin{tabular}{|l|c|}
\hline \multicolumn{1}{|c|}{ Atribute } & Weight \\
\hline Strata & 1.0 \\
\hline Sex & 0.689 \\
\hline Jurusan & 0.952 \\
\hline Kelas & 1.0 \\
\hline Seleksi & 0.084 \\
\hline Penghasilan Ayah & 0.696 \\
\hline Penghasilan Ibu & 0.566 \\
\hline IPK & 0.944 \\
\hline
\end{tabular}

Terlihat pada tabel di atas dengan menggunakan populasi size 5, maximum number of generations 30 (default), inertia weight 1.0 (default), local bestweight 1.0 (default), global best weight 1.0 (default) dan min weight 0.0 (default) mendapatkan hasil untuk weight 1 merupakan atribut yang paling berpengaruh pada proses klasifikasi dalam memprediksi kelulusan mahasiswa seperti atribut Strata dan kelas, untuk atribut Jurusan dan IPK juga berpengaruh yang terlihat pada hasil weight 0.9 dan untuk atribut lainnya kurang berpengaruh karena memiliki weight di bawah 0.9. hasil dari pembobotan tersebut selanjutnya di gunakan untuk pengujian nilai terbaik pada Particle Swarm Optimization. Dan untuk hasil akurasi pada algoritma Particle Swarm Optimization dengan menggunakan $\mathrm{K}$ terbaik mendapatkan hasil

Dengan mengubah Populasi Size yang dapat di lihat pada tabel Confusion Matrix di bawah ini:

Tabel 4.6 Confusion Matrix (Accuracy) data Mahasiswa dengan Population Size 10

\begin{tabular}{|c|c|c|c|}
\hline $\begin{array}{l}\text { accuracy: } 89.14 \%+/- \\
1.03 \% \text { (mikro: } 89.14 \% \text { ) }\end{array}$ & & & \\
\hline Population Size Ke 10 & $\begin{array}{l}\text { true. TIDAK TEPAT } \\
\text { WAKTU }\end{array}$ & $\begin{array}{l}\text { true. TEPAT } \\
\text { WAKTU }\end{array}$ & $\begin{array}{l}\text { class } \\
\text { precision }\end{array}$ \\
\hline $\begin{array}{l}\text { pred. TIDAK TEPAT } \\
\text { WAKTU }\end{array}$ & 266 & 51 & $83.91 \%$ \\
\hline pred. TEPAT WAKTU & 199 & 1787 & $89.98 \%$ \\
\hline Class recall & $57.20 \%$ & $97.23 \%$ & \\
\hline
\end{tabular}

Untuk memperoleh persentase hasil akurasi Algoritma Particle Swarm Optimization dengan Nilai $\mathrm{K}=14$ dan mengubah populasi size 10 dapat dicari dengan persamaan seperti pada pencarian akurasi Algoritma K-Nearest Neighbor dengan Nilai K $=14$ di atas.

5. Kesimpulan dan Saran

5.1 Kesimpulan

Berdasarkan hasil tahapan pengujian yang dilakukakan untuk mencari nilai optimasi terbaik dari dataset mahasiswa yang di teliti dapat di lihat pada Tabel 4.1 dan 
Tabel 4.4 bahwa dapat disimpulkan nilai Algoritma K-Nearest Neighbord dengan nilai terbaik yaitu $\mathrm{K}=14$ sejumlah $88.58 \%$ dapat meningkat dengan menggunakan algoritma Particle Swarm Optimization dengan patameter defult yaitu $88.97 \%$. Namun, saat menggunakan nilai $\mathrm{K}$ terbaik dan merubah parameter populasi size pada algoritma Particle Swarm Optimization untuk mencari nilai terbaik yang terdapat pada populasi size ke 10 mendapatkan nilai accuracy lebih tinggi sebesar 89.14\%, jadi saat menggunakan Algoritma K-Nearest Neighbord dan Algoritma K-Nearest Neighbord berbasis Particle Swarm Optimization dengan mencari nilai terbaik mendapatkan accuracy $88.58 \%$ menjadi $89.14 \%$ jadi meningkat sebesar $0.56 \%$. Tinggkat keakurasian biasanya dapat berubah - ubah sesuai dataset yang kita gunakan, semakin berkualitas sebuh dataset, semakin tinggi nilai accuracy yang didapatkan.

\subsection{Saran}

Walaupun dengan menggunakan model algoritma K-Nearest Neighbor berbasis Particle Swarm Optimization pada $\mathrm{K}=1$ dan parameter defult pada Particle Swarm Optimization yang sudah memberikan hasil yang lebih baik, namun ada bebera pahal yang dapat ditambahkan untuk penelitian selanjutnya:

1. Karena dataset yang digunakan penulis dalam atribut IPK bukan merupakan angka, yang pada saat pengolahan berpengaruh dalam hasil klasifikasi dan prediksi. Menyarankan jika menggunakan data Mahasiswa sebaiknya saat pengambilan data dilihat apakah IPK dalam bentuk angka atau tidak jika IPK yang menjadi Atribut dalam penentuan hasil.

2. Dengan menggunakan model yang telah dilakukan peneliti, diharapkan selanjutnya dapat menerapkan pada dataset yang berbeda.

3. Perlu menambahkan algoritma lainsehinga dapat menjadi bahan perbandingan untuk mendapatkan hasil yang lebih baik dari penelitian ini.

[1] UNIVERSITAS NEGERI GORONTALO, Pedoman Akademik. UNG Press, 2013.

[2] M. A. Banjarsari, H. I. Budiman, and A. Farmadi, "Penerapan K-Optimal Pada Algoritma Knn untuk Prediksi Kelulusan Tepat Waktu Mahasiswa Program Studi Ilmu Komputer Fmipa Unlam Berdasarkan IP

Sampai Dengan Semester 4," vol. 2, no. 2, pp. 50-64, 2015.

[3] L. H. Wandira Irene, Mukhlisulfatih Latief, "Penerapan Algoritma C5.0

Dalam Pengklasifikasian Data Mahasiswa Universitas

Negeri Gorontalo," 2014.

[4] K. Mu'arif, "Pemodelan data menggunakan c4.5 dan c4.5 berbasis particle swarm optimization untuk memprediksi kelulusan mahasiswa."

[5] A. Nirfah, "Klasifikasi Resiko Kredit Sepeda Motor Menggunakan Algoritma K-Nearest Neighbor Berbasis Particle Swarm Optimization," Universitas Dian Nuswantoro, 2016. 